\title{
Efeito do aquecimento e resfriamento de pisos no desempenho de matrizes e leitões
}

\author{
Haroldo Carlos Fernandes ${ }^{1}$, Ricardo Fontes Moreira ${ }^{2}$, Flavio Coutinho Longui ${ }^{3}$, Paula Cristina Rinaldi ${ }^{4}$, \\ Wagner da Cunha Siqueira ${ }^{5}$
}

\section{RESUMO}

O ambiente da criação intensiva de suínos influencia diretamente as condições de conforto e bem-estar animal; ambiente estressante provoca várias respostas, dependendo da capacidade de adaptação do animal, e as instalações têm como finalidade minimizar esses problemas. Objetivou-se, com este trabalho, avaliar o comportamento fisiológico e os índices zootécnicos das matrizes e dos leitões, com a utilização dos sistemas de aquecimento e resfriamento do piso. O delineamento experimental utilizado foi o inteiramente casualizado, no esquema fatorial em parcelas subdivididas, com cinco repetições para os tratamentos: piso aquecido para os leitões e resfriado para as matrizes (PCARA), piso sem aquecimento para os leitões e resfriado para as matrizes (PRCA) e piso sem modificação (PSMCA). Foram avaliados os parâmetros térmicos e fisiológicos das matrizes dos tratamentos PRCA e PCARA. O tratamento PRCA apresentou o melhor resultado, proporcionando maior conforto térmico para os animais, que atingiram em média um ganho 233 gramas por dia.

Palavras-chave: Instalações suinícolas, microclima, conforto térmico.

\section{ABSTRACT}

\section{Effect of heating and cooling of floors in the performance of lactating mothers and piglets}

The environment of the intensive farming of pigs directly influences their comfort and welfare; a stressful environment leads to various responses, depending on the adaptability of the animal. The facility aims to minimize these problems.The objective of this study was to evaluate the physiological and production indices of lactating mothers and piglets with the use of cooling systems and floor heating, respectively. The experimental design was completely randomized in a split plot with five replicates for the following treatments: heated floor for piglets and cooled to the parent (HPiCPa), no floor heating for piglets and cooled for the parent $(\mathrm{CPa})$ and floor without modification (FWM). We evaluated the thermal and physiological parameters of the arrays of treatments $\mathrm{CPa}$ and $\mathrm{HPiCPa}$. In the room designated S2 without modification, we evaluated the parameters of the matrices FWM treatment. Treatment CPa showed the best result, providing greater thermal comfort for the animals, which reached an average gain 233 grams per day.

Key words: Pig meat production facilities, microclimate, thermal comfort.

Recebido para publicação em 10/06/2010 e aprovado em 01/09/2011

Engenheiro Agrícola, Doutor. Departamento de Engenharia Agrícola, Universidade Federal de Viçosa, Avenida P.H Rolfs, s/n, 36570-000, Viçosa, Minas Gerais, Brasil. haroldo@ufv.br

${ }^{2}$ Engenheiro Mecânico, Doutor. Instituto Mineiro de Agropecuária-IMA, 36570-000 Viçosa, Minas Gerais, Brasil. rfontes@ gmail.com.br

${ }^{3}$ Zootecnista. Departamento de Engenharia Agrícola, Universidade Federal de Viçosa, Avenida P.H Rolfs, s/n, 36570-000, Viçosa, Minas Gerais, Brasil. flavio.longui@ufv.br ${ }^{4}$ Engenheira Agrícola, Doutor. Departamento de Engenharia Agrícola, Universidade Federal de Viçosa, Avenida P.H Rolfs, s/n, 36570-000, Viçosa, Minas Gerais, Brasil. paula.rinaldi@ufv.br

${ }^{5}$ Engenheiro Agrícola. Departamento de Engenharia Agrícola, Universidade Federal de Viçosa, Avenida P.H Rolfs, s/n, 36570-000, Viçosa, Minas Gerais, Brasil. wagner.siqueira@ufv.br 


\section{INTRODUÇÃO}

O ambiente da criação intensiva de suínos influencia diretamente as condições de conforto e bem-estar animal, interfere na manutenção térmica, na qualidade química do ar e nos comportamentos dos animais, afetando, ainda, o desempenho produtivo e reprodutivo (Pandorfi et al., 2007).

As instalações animais são construídas em função dos custos e das facilidades para o tratador, negligenciando o conforto animal. No caso da maternidade, esse problema se agrava, pois envolve duas categorias com exigências ambientais muito diferentes, a matriz suína que necessita ser refrigerada, e o leitão, que precisa ser aquecido (Tolon $\&$ Naas, 2005).

Um ambiente estressante provoca várias respostas, dependendo da capacidade de adaptação do animal. Em determinadas situações ambientais, o animal pode manter as suas funções vitais (mantença, reprodução e produção). É importante mencionar que a função vital prioritária do animal é a mantença (sobrevivência). Mas, tanto a mantença, quanto a reprodução e a produção estão sendo suprimidas à medida que o ambiente torna-se mais severo (Baêta \& Souza, 1997).

Nas matrizes, as altas temperaturas dentro das instalações influenciam negativamente a eficiência reprodutiva. Em locais onde as temperaturas no verão foram superiores a $24{ }^{\circ} \mathrm{C}$, foi observada, por Loves et al (1995), diminuição da fertilidade das fêmeas suínas, altas percentagens de retorno ao cio, atraso da maturidade sexual e maior mobilização de gordura corporal durante a lactação. Ao contrário, em regiões onde os dias quentes não ultrapassaram a temperatura de $24^{\circ} \mathrm{C}$, não foram observados efeitos significativos da alta temperatura sobre a fertilidade $\mathrm{e}$ taxa de concepção das fêmeas.

A perda de calor do leitão, logo após o nascimento tem, como consequências, o aumento da taxa metabólica do animal, os desvios de nutrientes, pois parte da energia utilizada para produção será utilizada na manutenção da temperatura corporal, a maior susceptibilidade às infecções enterogênicas e a morte nas primeiras horas de vida (Moraes et al. 1998).

Objetivou-se, com este trabalho, avaliar o comportamento, o conforto e a produtividade dos leitões e das matrizes lactantes, com a utilização dos sistemas de aquecimento e resfriamento dos pisos.

\section{MATERIAL E MÉTODOS}

O experimento foi realizado no Laboratório de Mecanização Agrícola, do Departamento de Engenharia Agrícola, e no setor de suinocultura do Departamento de Zootecnia, da Universidade Federal de Viçosa - MG, localizado à latitude de $20^{\circ} 45^{\prime} 45^{\prime \prime} \mathrm{S}$ e longitude de $42^{\circ} 52^{\prime}$
04" O, com altitude de 657 m. O clima da região, de acordo com a classificação de Köppen, é Cwa (quente, temperado, chuvoso, com estação seca no inverno e verão quente).

Após as avaliações preliminares, quando foram construídos protótipos dos pisos, para escolha do tipo de placa que seria utilizada, foram construídas oito placas para matriz suína e 16 placas para os leitões, com tubos corrugados embutidos em seu interior, em forma de serpentinas para circulação de água.

Os tratamentos experimentais analisados foram: piso sem aquecimento dos leitões e resfriado das matrizes, (PRCA); piso aquecido com água dos leitões e resfriado com água das matrizes, (PCARA); piso sem modificação, (PSMCA).

As placas foram montadas nas baias e entre elas foram colocados pedaços de madeira e de isopor, funcionando como isolantes e seções de expansão, com objetivo de evitar a troca de calor entre elas e de promover amortecimento devido à dilatação. Sobre as madeiras foram adaptados pedaços de tubos de PVC, que funcionaram como calhas para facilitar o escoamento da água dos bebedouros e da urina das matrizes lactantes, evitando-se, assim, a passagem de umidade para os pisos dos leitões.

Para a obtenção dos dados, foram instalados, na parte central de cada sala, um termômetro de globo negro, contendo, em seu interior o elemento sensor de um termômetro de vidro, com escala externa de leitura graduada de $10 \mathrm{a}+110^{\circ} \mathrm{C}$, resolução de $1^{\circ} \mathrm{C}$, e um higrômetro, composto com termômetros com escala de leitura externa de -10 a $+50{ }^{\circ} \mathrm{C}$, resolução de $1{ }^{\circ} \mathrm{C}$, posicionado a $1,50 \mathrm{~m}$ do piso, para a obtenção das temperaturas de globo negro, bulbo úmido e bulbo seco, respectivamente.

As leituras foram obtidas a cada hora, no intervalo de 8 às 18 horas, durante todos os dias, até o desmame. Os dados de temperatura de globo negro foram utilizados para os cálculos da temperatura radiante média (TRM), da carga térmica de radiação (CTR) e do índice de temperatura de globo e umidade (ITGU), e os dados das temperaturas de bulbo úmido e bulbo seco para determinação da umidade relativa do ar (UR) e da CTR. A velocidade do ar utilizada no cálculo do índice bioclimático (IBC) e CTR foram registradas com o uso de um anemômetro digital, com resolução de $0,01 \mathrm{~m} \mathrm{~s}^{-1}$.

As medidas das temperaturas de globo negro, bulbo seco e bulbo úmido foram obtidas apenas para a altura de 0,40 $\mathrm{m}$ do piso da gaiola. Os dados foram registrados, durante os 21 dias de permanência das matrizes suínas nas gaiolas, com leituras de uma em uma hora, durante as 24 horas. Com base nos dados coletados em cada horário, para cada tratamento, foram calculados os índices ITGU, a CTR e a UR, utilizando-se as equações: 
ITGU $=\operatorname{tgn}+0,36$ tpo $-330,08$

eq. 01

em que:

ITGU = índice de temperatura de globo e umidade, adimensional;

$\operatorname{tgn}=$ temperatura de globo negro, $\mathrm{K}$;

tpo $=$ temperatura do ponto de orvalho, $\mathrm{K}$.

A carga térmica radiante (CTR) expressa a radiação total recebida de todos os espaços, ou parte da vizinhança, e foi estabelecida por Esmay (1969).

A CTR pode ser obtida a partir da equação de StefanBoltzmann, ou seja:

$\mathrm{CTR}=\sigma(\mathrm{TRM})^{4}$

eq. 02

em que:

CTR = carga térmica de radiação, W.m ${ }^{-2}$;

$\sigma=$ constante de Stefan-Boltzmann, 5,67 x $10^{-8} \mathrm{~W} \cdot \mathrm{m}^{-2} \cdot \mathrm{K}^{-4}$; $\mathrm{TRM}=$ temperatura radiante média, $\mathrm{K}$.

A TRM pode ser obtida segundo a equação:

$\mathrm{TRM}=100 \sqrt[4]{2,51 \cdot \sqrt{\mathrm{v}} \cdot(\mathrm{Tgn}-\mathrm{Tbs})+(\operatorname{Tgn} / 100)^{4}}$ eq. 03

em que:

$\mathrm{v}=$ velocidade do $\mathrm{ar}, \mathrm{m} / \mathrm{s}^{-1}$;

Tbs = temperatura de bulbo seco, $\mathrm{K}$.

O índice desenvolvido para suínos, denominado de índice bioclimático (IBC), elaborado a partir da equação de Petit e relatado por Texier et al. (1979), baseia-se na sensação térmica do animal em função do equilíbrio existente entre a temperatura de bulbo $\operatorname{seco}\left(\mathrm{Tbs}, 0^{\circ} \mathrm{C}\right)$ ou de globo negro (Tgn, $0{ }^{\circ} \mathrm{C}$ ), da umidade relativa do ar (UR, $\%)$, da velocidade do vento $\left(\mathrm{v}, \mathrm{m} \mathrm{s}^{-1}\right)$, da variação do peso animal $(\mathrm{P}, \mathrm{kg})$ e da temperatura retal $\left(\mathrm{TR}, 0^{\circ} \mathrm{C}\right)$, e é expressa pela seguinte equação:

$\mathrm{IBC}=0,89 \mathrm{TBS}+0,05 \mathrm{UR}-1,81 \mathrm{v}+0,02 \mathrm{P}-0,543 \mathrm{TR}$ eq. 04

Para determinação da umidade relativa do ar, foi utilizado um termo-higrômetro marca Instrutherm.

Utilizou-se o modelo em parcelas subdivididas, com nove tratamentos nas parcelas, dispostas no delineamento inteiramente casualizado, com cinco repetições, sendo as parcelas, os três tipos de pisos e, as subparcelas, os três intervalos de idade: 0-7; 7-14, 14-21 dias.

Para as variáveis índice de temperatura de globo e umidade (ITGU), carga térmica de radiação (CTR) e umidade relativa do ar (UR), o tempo de medição em horas constituiu as subparcelas. Para a variável frequência respiratória $(\mathrm{FR})$, temperatura retal (TR) e índice bioclimático das matrizes (IBC), as subparcelas foram constituídas pelos dois períodos (manhã e tarde). O peso médio dos leitões aos 21 dias de idade (PML) e o ganho médio de peso diário dos leitões (GMDL) foram analisados, tendo como subparcelas os três intervalos de idade.

\section{RESULTADOS E DISCUSSÃO}

O resumo da análise de variância dos dados do índice de temperatura de globo e umidade (ITGU), da carga térmica de radiação (CTR) e da umidade relativa do ar (UR) estão apresentados na Tabela 1. Esses dados foram em função da hora do dia $(\mathrm{H})$ correspondente aos tratamentos experimentais das salas $\mathrm{S}_{1}$ e $\mathrm{S}_{2}$ : piso sem aquecimento para os leitões e resfriado para matriz, com animais (PRCA); piso aquecido para os leitões e resfriado para a matriz, com animais (PCARA) e piso sem modificação sala $\mathrm{S}_{2}$, com animais (PSMCA).

Na Tabela 1, observa-se que, com relação ao ITGU, não houve diferença significativa entre os tratamentos (T) e interação T x H, a 5\% de probabilidade. Houve diferença significativa apenas nas horas do dia $(\mathrm{H})$ a $1 \%$ de probabilidade.

A Figura 1 ilustra os resultados observados e estimados pelas equações de regressão, para os três tratamentos, e do ambiente interno das salas $\mathrm{S}_{1}$ e $\mathrm{S}_{2}$, em função da hora do dia. O modelo que melhor se ajustou foi o de sexto grau.

Estudando os efeitos da ventilação e do resfriamento evaporativo para as matrizes suínas em lactação, Turco (1993) observou que o ITGU crítico superior foi em torno de 72, corroborado pelo aumento da frequência respiratória e temperatura retal, o que evidenciou a ocorrência de desconforto térmico, conforme mostrado na Figura 1.

Na Tabela 1, observa-se que, com relação a CTR, não houve diferença significativa entre os tratamentos (T) e interação $\mathrm{T}$ x H, a $5 \%$ de probabilidade.

Na Figura 2, são apresentados os resultados observados e estimados pelas equações de regressão, para os três tratamentos e do ambiente interno das salas $S_{1}$ e $S_{2}$ em função da hora do dia. O modelo que melhor se ajustou foi o de sexto grau.

Turco (1993) observou que a CTR crítica superior é em torno de 465 W.m-2, corroborado pelo aumento da frequência respiratória e da temperatura retal, o que evidenciou a ocorrência de desconforto térmico.

Observa-se, na Figura 2, que nenhum dos tratamentos apresentou valores acima do limite crítico superior de conforto térmico estimado por Turco (1993), indicando que durante a realização do experimento as instalações das salas foram suficientes para eliminar o desconforto térmico, em relação à CTR, inclusive no interior das baias. 
Na Tabela 1, observa-se que, com relação à UR, não houve diferença significativa entre os tratamentos (T) e interação T x H, a 5\% de probabilidade. Houve diferença significativa apenas nas horas do dia $(\mathrm{H})$, a $1 \%$ de probabilidade.

Na Figura 3, são apresentados os resultados observados e estimados pelas equações de regressão, para os três tratamentos, em função da hora do dia. O modelo que melhor se ajustou foi o de quarto grau.

Como se pode observar pela Figura 3, em ambos os tratamentos, na maior parte do tempo, os valores obtidos de UR's apresentaram-se acima da faixa de conforto térmico. Apenas nos horários de temperaturas mais elevadas, os tratamentos PRCA e PSMCA apresentaram UR's nas faixas

Tabela 1. Resumo das análises de variância referentes aos efeitos do tratamento $(\mathrm{T})$ e da hora do dia $(\mathrm{H})$, com relação à média do índice de temperatura de globo e umidade (ITGU), da carga térmica de radiação (CTR), em W.m ${ }^{-2}$, e da umidade relativa do ar (UR), em percentagem

\begin{tabular}{lcccc}
\hline \multirow{2}{*}{ FV } & GL & ITGU & \multicolumn{2}{c}{ Quadrados médios } \\
\cline { 4 - 5 } & & & CTR & UR \\
\hline Tratamento & 2 & 7,2569 & 259,593 & 1326,933 \\
Resíduo A & 12 & 63,6655 & 2176,236 & 516,538 \\
H & 23 & $252,2556 * *$ & $5409,217 * *$ & $418,362 * *$ \\
T x H & 46 & 0,3727 & 3,624 & 8,080 \\
Resíduo B & 276 & 0,8153 & 17,171 & 13,164 \\
\hline \multirow{2}{*}{ CV\% } & Parcela & 11,67 & 11,04 & 28,24 \\
& Subparcela & 1,32 & 0,98 & 4,51 \\
\hline
\end{tabular}

**Significativo a $1 \%$ de probabilidade, pelo teste $\mathrm{F}$.

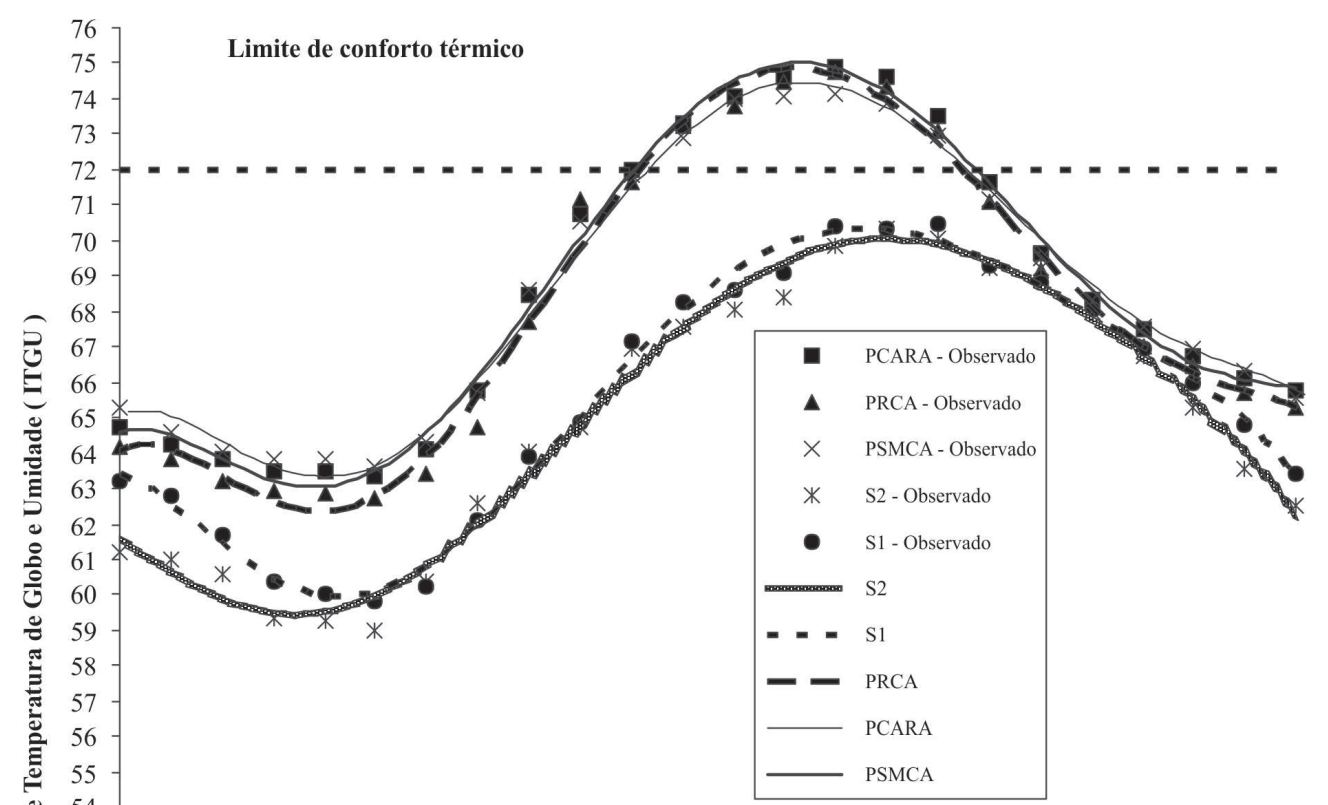

S1: ITGU $=61,59-0,919 * * H-0,0643 * * H^{2}+0,06237 * * H^{3}-0,006256 * * H^{4}+0,0002768 * * H^{5}-0,00000342 * * H^{6} R^{2}=0,98$ S2: ITGU $=63,43-0,513 * * H-0,4916 * * H^{2}-0,14683 * * H^{3}-0,013225 * * H^{4}+0,0005542 * * H^{5}-0,00000712 * * H^{6} \quad R^{2}=0,99$ PCARA: ITGU $=64,57+0,590 * * \mathrm{H}-0,8238^{* *} \mathrm{H}^{2}+0,20837 * * \mathrm{H}^{3}-0,018247 * * \mathrm{H}^{4}+0,0006672 * * \mathrm{H}^{5}-0,00000878^{* * *} \mathrm{H}^{6} \quad \mathrm{R}^{2}=0,99$ PRCA: ITGU $=64,08+0,815 * * \mathrm{H}-0,9998 * * \mathrm{H}^{2}+0,24647 * * \mathrm{H}^{3}-0,021644 * * \mathrm{H}^{4}+0,0008017 * * \mathrm{H}^{5}-0,00000935^{* *} \mathrm{H}^{6} \quad \mathrm{R}^{2}=0,99$ PSMCA: ITGU $=65,12+0,401 * * \mathrm{H}-0,7805 * * \mathrm{H}^{2}+0,20499 * * \mathrm{H}^{3}-0,018402 * * \mathrm{H}^{4}+0,0006904 * * \mathrm{H}^{5}-0,00000935 * * \mathrm{H}^{6} \quad \mathrm{R}^{2}=0,99$ $\begin{array}{llllllllllllllllllllllllllllll}0 & 1 & 2 & 3 & 4 & 5 & 6 & 7 & 8 & 9 & 10 & 11 & 12 & 13 & 14 & 15 & 16 & 17 & 18 & 19 & 20 & 21 & 22 & 23 & 24\end{array}$ Horas do dia

** Significativo a $1 \%$ de probabilidade, pelo teste $\mathrm{F}$.

Figura 1. Equações de regressão ajustadas, coeficiente de determinação $\left(\mathrm{R}^{2}\right)$ para a estimativa do índice de temperatura de globo e umidade (ITGU), em função da hora do dia (H), para os tratamentos avaliados. 


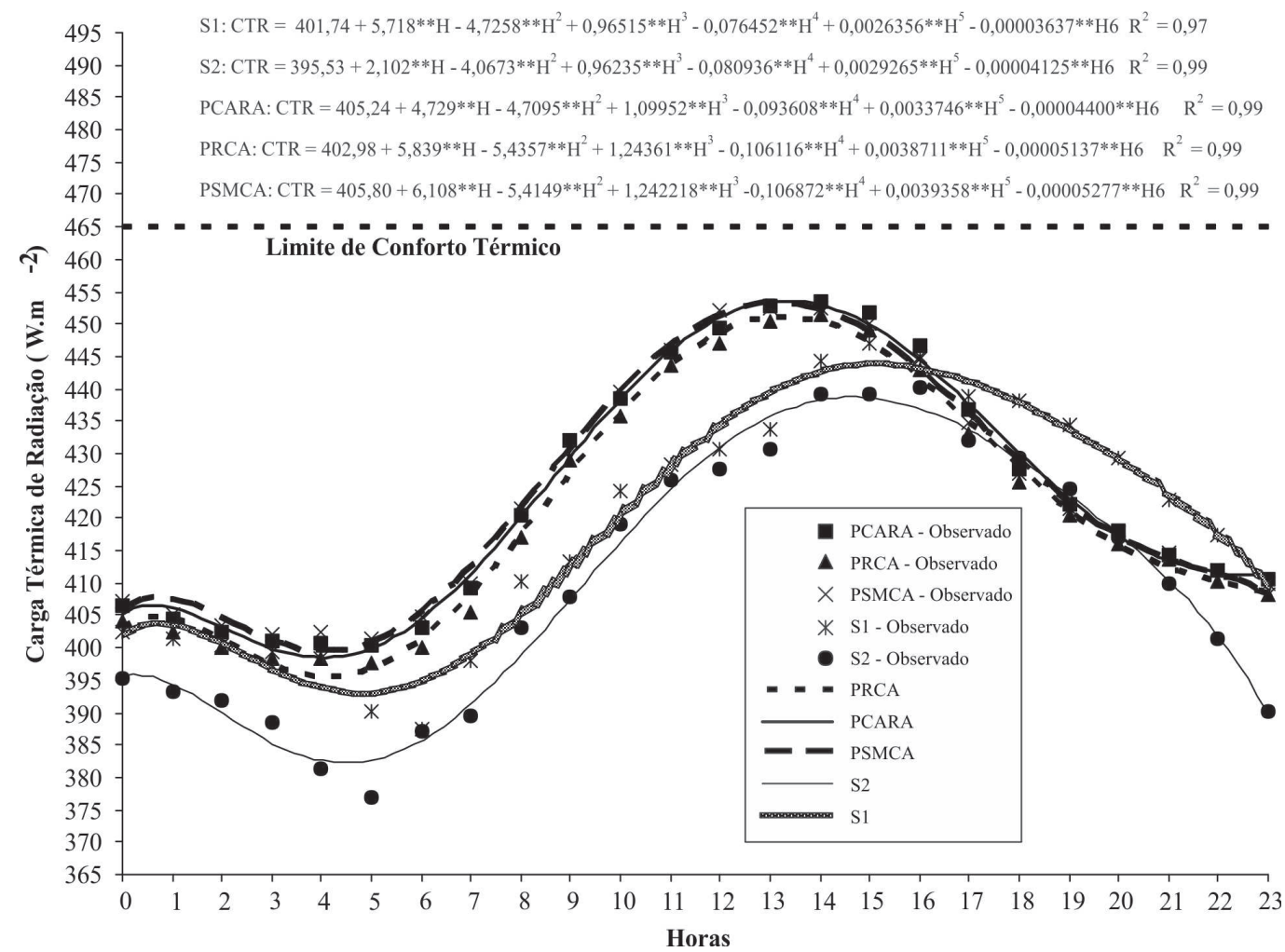

** Significativo a $1 \%$ de probabilidade, pelo teste $\mathrm{F}$.

Figura 2. Equações de regressão ajustadas, coeficiente de determinação $\left(\mathrm{R}^{2}\right)$ para a estimativa da carga térmica radiante (CTR), em W.m ${ }^{-2}$, em função da hora do dia $(\mathrm{H})$, para os tratamentos avaliados.

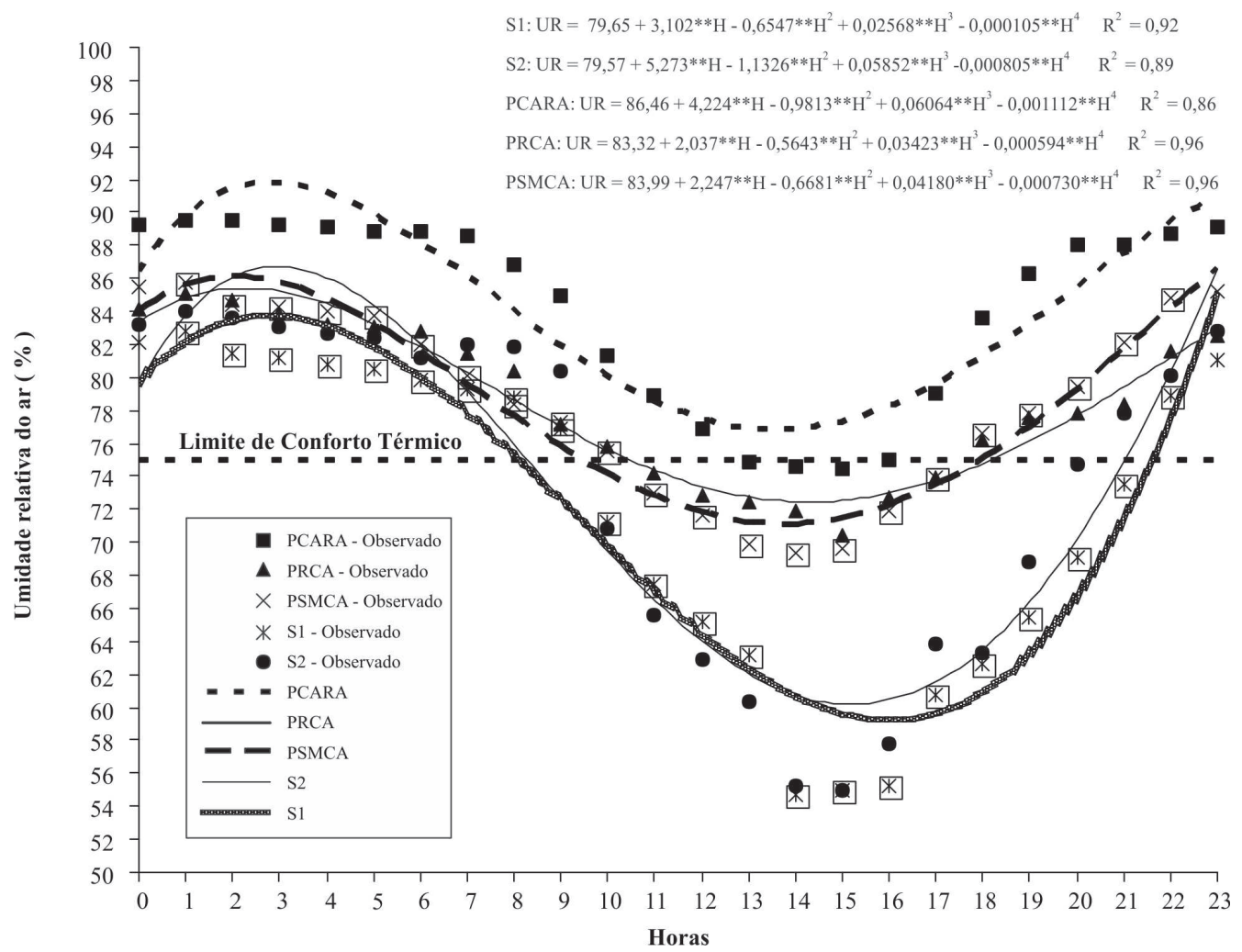

** Significativo a $1 \%$ de probabilidade, pelo teste $\mathrm{F}$.

Figura 3. Equações de regressão ajustadas, coeficiente de determinação $\left(\mathrm{R}^{2}\right)$ para estimativa da umidade relativa do ar (UR), em percentagem, em função da hora do dia $(\mathrm{H})$, para os tratamentos avaliados. 
do limite de conforto térmico, citados pelos autores Veit e Troutt (1982), que estabeleceram, como valores ótimos de UR, para matriz suína lactante, a faixa de 55 a $75 \%$. Por outro lado, Benedi (1986) estabeleceu que, para temperatura do ar de até $27^{\circ} \mathrm{C}$, a UR considerada ótima para maternidade de suínos está compreendida na faixa de 70 a $80 \%$.

O tratamento PCARA em todos os horários estudados apresentou valores de UR acima do limite de conforto térmico na faixa estipulada por Veit e Troutt (1982), porém, nos horários de temperaturas mais elevadas, ficou dentro da faixa estabelecida por Benedi (1986).

As mudanças de comportamento dos animais ocorreram com maior frequência e intensidade para as matrizes do tratamento PSMCA, principalmente nos horários de maior elevação das temperaturas, de 11 às 18 horas, horários estes que apresentaram os menores valores de UR, mostrando que os valores encontrados, mesmo estando dentro da faixa recomendada por Veit e Troutt (1982), não foram suficientes para proporcionar conforto para as matrizes do tratamento PSMCA, durante a realização do experimento.

A Tabela 2 apresenta os resumos das análises de variância referentes aos efeitos dos tratamentos experimentais: piso aquecido dos leitões e resfriado para as matrizes, com animais (PCARA); piso sem aquecimento para os leitões e resfriado para as matrizes, com animais (PRCA) e piso sem modificação $\mathrm{S}_{2}$, com animais (PSMCA).

Não foi verificada diferença significativa entre os tratamentos $(\mathrm{T})$ e interação tratamentos $\mathrm{x}$ horários de coleta, a $5 \%$ de probabilidade. Foi verificada diferença significativa, a $1 \%$ de probabilidade, apenas nos períodos (manhã e tarde) de coletas.

$\mathrm{Na}$ Tabela 3, encontram-se as médias do índice bioclimático, para cada tratamento, nos períodos da manhã ( 8 horas) e da tarde (15 horas).

Segundo Texier et al. (1979), as condições de neutralidade térmica devem ser obtidas para o valor de IBC igual a zero, tendo como limite crítico superior de conforto térmico para as matrizes suínas em lactação, igual a dois.

Tabela 2. Resumo da análise de variância referente aos efeitos do tratamento $(\mathrm{T})$ e do período do dia $(\mathrm{P})$, sobre o índice bioclimático (IBC)

\begin{tabular}{lcc}
\hline \multirow{2}{*}{ FV } & GL & Quadrados médios \\
\cline { 3 - 3 } & & IBC \\
\hline Tratamento & 2 & 0,1579 \\
Resíduo A & 12 & 0,7845 \\
P & 1 & $235,6482^{* *}$ \\
T x P & 2 & 1,5636 \\
Resíduo B & 12 & 1,5217 \\
\hline CV\% & Parcela & 14,01 \\
& Subparcela & 19,51 \\
\hline
\end{tabular}

** Significativo a $1 \%$ de probabilidade, pelo teste $\mathrm{F}$.
Porém, Perdomo (1995), estudando o efeito de três sistemas de ventilação, demonstrou a existência de um ambiente quente em todos os horários de todos os tratamentos, superando, em 202,5, 302 e 237\%, para IBC igual a dois, o que, segundo Turco (1997), significa que, provavelmente, o IBC foi desenvolvido para condições ambientais com temperatura e umidade menores do que as do sul do Brasil e com animais menos adaptados às condições ambientais existentes nessa região.

Baseando-se nos valores encontrados por Turco (1993), Perdomo (1995), Turco (1997), pode-se concluir que os valores de IBC mantiveram-se dentro da faixa de conforto para as matrizes lactantes, já que a maioria das medidas de velocidade do vento apresentou valores iguais ou próximos de zero, isto ocorreu pela razão de a região onde se realizou o experimento estar localizada entre montanhas.

A Tabela 4 apresenta o resumo das análises de variância referentes aos efeitos dos tratamentos experimentais: piso aquecido dos leitões e resfriado para as matrizes, com animais (PCARA); piso sem aquecimento para os leitões e resfriado para as matrizes suínas, com animais (PRCA) e piso sem modificação $\mathrm{S}_{2}$, com animais (PSMCA); com cinco repetições de cada, e do período (P) - manhã e tarde - com relação às médias de frequência respiratória (FR) e da temperatura retal (TR) das matrizes.

De acordo com a Tabela 4, pode-se observar que houve diferença significativa entre os tratamentos para $(\mathrm{P}<0,05)$ apenas para a frequência respiratória $(\mathrm{FR})$ das matrizes. O período $(\mathrm{P})$, caracterizado por manhã e tarde, apresentou diferenças significativas entre os tratamentos, tanto para a FR como TR das matrizes para $\mathrm{P}<0,01$. Com relação à interação $\mathrm{T} x \mathrm{P}$, houve diferença significativa para $\mathrm{P}<0,01$ entre os tratamentos, apenas com relação à frequência respiratória (FR).

$\mathrm{Na}$ Tabela 5, encontram-se as médias da frequência respiratória das matrizes, em respirações por minuto, para cada tratamento nos períodos da manhã ( 8 horas) e da tarde (15 horas). No período da manhã, não houve diferença significativa entre as médias da FR das matrizes, ocorrendo, apenas, na parte da tarde, entre os tratamentos PRCA e PCARA, em relação à PSMCA.

Pode-se verificar que os valores encontrados nos tratamentos PRCA e PCARA, mesmo nos períodos de tem-

Tabela 3. Valores médios do índice bioclimático (IBC), com relação ao período de observações

\begin{tabular}{lccc}
\hline \multirow{2}{*}{ Período } & \multicolumn{3}{c}{ Tratamentos } \\
\cline { 2 - 4 } & PRCA & PCARA & PSMCA \\
\hline Manhã & $3,04 \mathrm{~B}$ & $3,63 \mathrm{~B}$ & $3,99 \mathrm{~B}$ \\
Tarde & $8,91 \mathrm{~A}$ & $8,93 \mathrm{~A}$ & $8,94 \mathrm{~A}$ \\
\hline
\end{tabular}

Médias seguidas de pelo menos uma mesma letra, na coluna, não diferem entre si, pelo teste Newman-Keuls a $5 \%$ de probabilidade.

Rev. Ceres, Viçosa, v. 58, n.6, p. 701-709, nov/dez, 2011 
peraturas elevadas, mantiveram-se dentro da faixa de controle térmico citada por Carvalho (1981), que considerou, como padrão fisiológico normal para matrizes em lactação, a temperatura retal entre 37,8 e $39,4^{\circ} \mathrm{C}$ e a frequência respiratória na faixa de 10 a 40 movimentos respiratórios por minuto. Já para o tratamento PSMCA, algumas matrizes atingiram valores acima dos relatados por Carvalho (1981), evidenciando desconforto térmico para elas.

Na Tabela 6, são apresentados os valores médios da temperatura retal das matrizes para cada tratamento nos períodos da manhã ( 8 horas) e da tarde (15horas).

Não foi observada diferença entre os tratamentos, a $5 \%$ de probabilidade, conforme Tabela 6.

Tomando-se como base os valores citados por Carvalho (1981), todos os tratamentos, apresentaram valores médios de temperaturas retais dentro da faixa de limite de conforto térmico.

Todas as matrizes no período da tarde apresentaram uma elevação na TR e na FR, provocada pela elevação da temperatura ambiente, que evidenciou desconforto térmico nas matrizes, pois segundo Esmay (1969), em condições de estresse por calor, as matrizes suínas primeiro aumentam a frequência respiratória, na tentativa de manter a homeotermia. Persistindo o estresse, por meio de mecanismos fisiológicos de eliminação de calor, aumentam a temperatura corporal, refletida por meio da TR. Como apenas as matrizes suínas dos tratamentos PSMCA apresentaram elevação da frequência térmica acima dos valo-

Tabela 4. Resumo da análise de variância referente ao efeito do período $(\mathrm{P})$ e dos tratamentos $\mathrm{T}$, sobre a frequência respiratória (FR) e a temperatura retal das matrizes (TR)

\begin{tabular}{lccc}
\hline & \multicolumn{3}{c}{ Quadrados médios } \\
\cline { 2 - 4 } FV & GL & FR & TR \\
\hline Tratamento & 2 & $746,2333 *$ & 0,0301 \\
Resíduo A & 12 & 156,2833 & 0,2139 \\
P & 1 & $662,7000^{* *}$ & $2,3130 * *$ \\
T x P & 2 & $126,1000^{* *}$ & 0,1152 \\
Resíduo B & 12 & 15,5500 & 0,0309 \\
\hline CV\% & Parcela & 43,46 & 1,19 \\
& Subparcela & 13,71 & 0,45 \\
\hline
\end{tabular}

$*$ e **Significativos a 5 e $1 \%$ de probabilidade, pelo teste $\mathrm{F}$.

Tabela 5. Valores médios da frequência respiratória das matrizes (FR), em respirações por minuto, com relação ao período de observação (manhã e tarde) para os tratamentos

\begin{tabular}{lccc}
\hline Período & \multicolumn{3}{c}{ Tatamentos } \\
\cline { 2 - 4 } & PRCA & PCARA & PSMCA \\
\hline Manhã & $19,80 \mathrm{Ba}$ & $22,60 \mathrm{Ba}$ & $29,80 \mathrm{Ab}$ \\
Tarde & $25,00 \mathrm{Ba}$ & $28,00 \mathrm{Ba}$ & $47,10 \mathrm{Aa}$
\end{tabular}

Médias seguidas de pelo menos uma mesma letra maiúscula, na linha, e minúscula, na coluna, não diferem entre si, pelo teste Newman-Keuls a $5 \%$ de probabilidade. res citados por Carvalho (1981), subentende-se que utilizaram o primeiro mecanismo na tentativa de manter a homeotermia, chegando à utilização do segundo mecanismo de elevação da temperatura corporal apenas algumas vezes.

O resumo da análise de variância do ganho de peso diário dos leitões (GPDL) está apresentado na Tabela 7. Observa-se que não houve diferença significativa entre os tratamentos (T) e na interação (T x I), a 5\% de probabilidade. Quanto aos intervalos de idade (I), foi apresentada diferença significativa, a $1 \%$ de probabilidade.

$\mathrm{Na}$ Tabela 8, encontram-se as médias do ganho de peso diário dos leitões (GPDL), em gramas por dia, de acordo com os intervalos de idade para cada tratamento. Pode-se verificar que, estatisticamente, só houve diferença significativa no ganho de peso diário (GPDL), com relação à variável intervalo de idade.

Fazendo uma extrapolação do ganho obtido durante 21 dias, pode-se verificar que, para as relações: PRCA PCARA: o ganho do tratamento PRCA será de aproximadamente 546g, em relação ao tratamento PCARA; PRCA PSMCA: o ganho do tratamento PRCA será de aproximadamente 1071g, em relação ao tratamento PSMCA; PCARA - PSMCA; o ganho do tratamento PCARA será de aproximadamente $525 \mathrm{~g}$, em relação ao tratamento PSMCA.

Como se pode verificar nas relações acima citadas, os tratamentos PRCA e PCARA apresentaram resultados satisfatórios de ganho de peso em relação ao sistema de testemunha PSMCA, obtido por meio das melhores con-

Tabela 6. Valores médios da temperatura retal das matrizes (TR), em ${ }^{\circ} \mathrm{C}$, com relação ao período de observação (manhã e tarde) para os tratamentos

\begin{tabular}{lccc}
\hline \multirow{2}{*}{ Período } & \multicolumn{3}{c}{ Tatamentos } \\
\cline { 2 - 4 } & PRCA & PCARA & PSMCA \\
\hline Manhã & $38,75 \mathrm{~B}$ & $38,59 \mathrm{~B}$ & $38,46 \mathrm{~B}$ \\
Tarde & $39,06 \mathrm{~A}$ & $39,23 \mathrm{~A}$ & $39,17 \mathrm{~A}$ \\
\hline Médias seguidas com pelo menos uma mesma letra, na coluna, não \\
diferem entre si, pelo teste Newman-Keuls a 5\% de probabilidade.
\end{tabular}

Tabela 7. Resumo da análise de variância referente ao efeito dos tratamentos (T) e dos intervalos de idade (I), sobre o ganho de peso diário dos leitões (GPDL)

\begin{tabular}{lcc}
\hline \multirow{2}{*}{ FV } & \multicolumn{2}{c}{ Quadrados médios } \\
\cline { 2 - 3 } & GL & GLDL \\
\hline Tratamento & 2 & 9630,422 \\
Resíduo A & 12 & 5452,844 \\
I & 1 & $22294,690 * *$ \\
T x I & 4 & 451,922 \\
Resíduo B & 21 & 1231,094 \\
\hline CV\% & Parcela & 35,63 \\
& Subparcela & 16,93 \\
\hline
\end{tabular}

** Significativo $1 \%$ de probabilidade, pelo teste $\mathrm{F}$.

Rev. Ceres, Viçosa, v. 58, n.6, p. 701-709, nov/dez, 2011 
Tabela 8. Valores médios do ganho de peso diário dos leitões (GPDL), em gramas por dia, referentes a intervalos de idade dos leitões para os tratamentos

\begin{tabular}{lcccc}
\hline \multirow{2}{*}{ Idade (dias) } & \multicolumn{4}{c}{ Variação média de ganho de peso diário $\left(\mathbf{g ~ d i a}^{-1}\right)$} \\
\cline { 2 - 4 } & PRCA & PCARA & PSMCA & Médias \\
\hline $00-07$ & 184 & 175 & 134 & $164 \mathrm{~b}$ \\
$07-14$ & 252 & 209 & 195 & $219 \mathrm{a}$ \\
$14-21$ & 262 & 236 & 218 & $239 \mathrm{a}$ \\
\hline Médias & $233 \mathrm{~A}$ & $207 \mathrm{~A}$ & $182 \mathrm{~A}$ & \\
\hline
\end{tabular}

Médias seguidas por pelo menos uma mesma letra maiúscula, na linha, e minúscula, na coluna, não diferem entre si, pelo teste NewmanKeuls a $5 \%$ de probabilidade.

dições ambientais fornecidas para as matrizes. Quanto à relação PRCA - PCARA, ocorreu diferença relevante, atribuída à época da realização do experimento, com predominância de temperaturas elevadas; o que veio a favorecer as matrizes do tratamento PRCA. Espera-se que em situações de temperaturas ambientais menos elevadas ocorra o contrário, porque o sistema de aquecimento favorecerá mais os leitões e ao mesmo tempo diminuirá a incidência de calor no microambiente da matriz lactante, causada pelo aquecimento. Na relação PCARA - PSMCA, o resultado também foi importante, fisiologicamente, para o tratamento PCARA, obtido em razão das melhores condições fornecidas para os leitões e matrizes, em relação às do tratamento PSMCA.

O resumo da análise de variância, referente ao efeito dos tratamentos sobre a média de peso dos leitões aos 21 dias de idade, é apresentado na Tabela 9. Observa-se que não houve diferença significativa entre os tratamentos, a $5 \%$ de probabilidade.

Embora a análise de variância não tenha detectado diferença significativa entre os tratamentos, a $5 \%$ de probabilidade, o peso médio dos leitões dos tratamentos PRCA e PCARA foi, em média, de 18,1 e 8,74\%, respectivamente, superiores aos dos animais alojados no tratamento sem modificação (PSMCA). Embora não seja significativa, esta diferença pode representar, no final de um ciclo produtivo, um ganho financeiro para o produtor rural.

O peso médio dos leitões (PML), com desmame aos 21 dias de idade, está apresentado na Tabela 10.

Roppa (1996) classificou o desempenho dos leitões na maternidade como: bom, quando, na desmama (21 dias), o peso médio for superior a $6,0 \mathrm{~kg}$; médio, entre 5,7 e 6,0 $\mathrm{kg}$; ruim quando for inferior a $5,7 \mathrm{~kg}$. Com base nos dados

Tabela 9. Resumo da análise de variância referente ao efeito dos tratamentos ( $\mathrm{T}$ ) sobre a média de peso dos leitões aos 21 dias de idade

\begin{tabular}{lcc}
\hline FV & GL & PML \\
\hline Tratamento & 2 & $1,812^{\text {n.s. }}$ \\
Resíduo & 12 & 0,899 \\
\hline CV \% & & 15,79 \\
\hline
\end{tabular}

N.s.: não significativo a $5 \%$ de probabilidade, pelo teste $\mathrm{F}$. da Tabela 11, foi efetuada a classificação do peso médio dos leitões, para avaliação do desempenho de cada tratamento.

Como se pode observar nos tratamentos PRCA e PCARA, apenas $20 \%$ das matrizes estudadas apresentaram médias consideradas ruins, sendo que com as matrizes do tratamento PSMCA ocorreu o contrário; ou seja, $80 \%$ apresentaram-se a classificação ruim, significando dizer que as modificações proporcionaram uma melhora significativa no desempenho das matrizes.

Tabela 10. Média de peso dos leitões aos 21 dias de idade, em kg

\begin{tabular}{|c|c|c|c|}
\hline \multirow{2}{*}{ Médias } & \multicolumn{3}{|c|}{ Média de peso dos leitões aos 21 dias, em kg } \\
\hline & PRCA & PCARA & PSMCA \\
\hline & 6,63 & 5,95 & 5,43 \\
\hline
\end{tabular}

Tabela 11. Peso médio dos leitões (PML) na época do desmame (21 dias), seguindo a classificação de ROPPA (1996)

\begin{tabular}{lccc}
\hline \multirow{2}{*}{ Repetições } & \multicolumn{3}{c}{$\begin{array}{c}\text { Média de peso dos leitões } \\
\text { aos } 21\end{array}$} \\
& PRCA & PCAR de idade, em kg \\
\hline 1 & $7,33 \mathrm{~B}$ & $6,68 \mathrm{~B}$ & PSMCA \\
\hline 2 & $5,91 \mathrm{M}$ & $6,37 \mathrm{~B}$ & $6,61 \mathrm{R}$ \\
3 & $7,93 \mathrm{~B}$ & $4,26 \mathrm{R}$ & $5,02 \mathrm{R}$ \\
4 & $6,62 \mathrm{~B}$ & $6,40 \mathrm{~B}$ & $5,39 \mathrm{R}$ \\
5 & $5,38 \mathrm{R}$ & $6,02 \mathrm{~B}$ & $5,34 \mathrm{R}$ \\
\hline
\end{tabular}

B - bom; $\mathrm{M}$ - médio; $\mathrm{R}$ - ruim.

** Significativo a $1 \%$ de probabilidade, pelo teste $\mathrm{F}$.

\section{CONCLUSÕES}

Pode-se adotar um limite superior de conforto térmico para as matrizes lactantes, desde que se utilize o sistema de resfriamento do piso das matrizes de suínos.

O tratamento PRCA proporciona as melhores condições térmicas ambientais e fisiológicas para as matrizes lactantes, seguido pelo tratamento PCARA.

O sistema de aquecimento do piso proporciona um bom conforto térmico para os leitões.

Rev. Ceres, Viçosa, v. 58, n.6, p. 701-709, nov/dez, 2011 


\section{REFERÊNCIAS}

Baeta FC \& Souza CF (1997) Ambiência em edificações rurais: Conforto animal. Viçosa, UFV. 246p.

Benedi JMH (1986) El ambiente de los alojamientos ganaderos. Madrid, Ministério da Agricultura, Pesca y Alimentacion, Servicio de Extension Agrária. 28p.

Carvalho LFOS (1981) Determinação dos padrões normais e da influência do sexo, do período de cio, da gestação, do parto e da raça sobre a freqüência respiratória, freqüência cardíaca e temperatura retal de suínos (Sus Scrofe) criados no Estado de São Paulo. Dissertação de Mestrado. Universidade Federal de Viçosa. Viçosa. 43p.

Esmay ML (1969) Principles of animal environnental Environmental Engineering in Agriculture and Food Series. Westport, The AVI Publishing Company, Inc. 325p.

Love RJ, Klupiec C, Thornton EJ \& Evan G (1995) An interaction between feeding rate and season affects fertility of sows. Animal Reproduction Science, 39:275-284

Mores N, Sobertiansky J, Wentz I \& Moreno AM (1998) Manejo do leitão desde o nascimento até o abate. In: Sobestiansky I, Wentz I, Silveira PRS \& Sesti LAC (Eds.) Suinocultura Intensiva. Concórdia, Embrapa. p.135-161.
Pandorfi H, Silva IJO, Guiselini C \& Piedade SMS (2007) Uso da lógica fuzzy na caracterização do ambiente produtivo para matrizes gestantes. Engenharia Agrícola, 27:83-92.

Perdomo CC (1995) Avaliação de sistemas de ventilação sobre o condicionamento ambiental e o desempenho de suínos na fase de maternidade. Tese de Doutorado. Universidade Federal do Rio Grande do Sul, Porto Alegre. 239p.

Roppa LA (1996) Suinocultura em números. In: Seminário Internacional de Suinocultura, São Paulo. Anais, USP. p.1-16.

Texier C, Farce B \& Granier R (1979) Influence des variations des principaux facteurs de l'ambiance na porcherie d'engraissment. Jounnie de lá Recherch Porcine en France, 12:153-164.

Tolon YB \& Naas IA (2005) Avaliação de tipos de ventilação em maternidade de suínos. Engenharia Agrícola, 25:565-574.

Turco SHN (1993) Modificações das condições ambientais de verão, em maternidade de suínos. Dissertação de Mestrado. Universidade Federal de Viçosa, Viçosa. 58p.

Turco SHN (1997) Análise de sistemas de acondicionamento térmico em maternidade para suínos. Dissertação de Doutorado. Universidade Federal de Viçosa, Viçosa. 93p.

Veit HP \& Troutt HF (1982) Monitoring air quality for livestock respiratory health. Veterinary Medicine and Small Animal Clinican, 77:454-464. 